\title{
Percutaneous nephrolithotomy versus flexible ureteroscopic lithotripsy in the treatment of upper urinary tract stones: a meta-analysis comparing clinical efficacy and safety
}

Yeda Chen ${ }^{\dagger}$, Yaoan Wen ${ }^{\dagger}$, Qingfeng Yư ${ }^{\dagger}$, Xiaolu Duan, Wenqi Wu and Guohua Zeng ${ }^{*}$

\begin{abstract}
Background: Upper urinary tract stones is the most common diseases in urology. Percutaneous nephrolithotomy (PCNL) and ureteroscopic lithotripsy (fURL) are common treatment, but both their efficacy and safety are controversial. Thus we aim to evaluate the efficacy and safety of PCNL and fURL in the treatment of upper urinary tract stones, providing a reference for clinical work.

Methods: PubMed, Web of Science, Embase and CNKI were searched through Apr. 1, 2019 to identify eligible studies. Data were analyzed by using RevMan 5.3 and Stata 12.0 software. Pooled relative risks (RRs) or weighted mean difference (WMD) with 95\% confidence intervals (Cls) were calculated using fixed or random effects methods. Publication bias and sensitivity analysis were performed.

Results: Four randomized controlled trials (RCTs), fifteen cohort studies involving 1822 patients were included. Stone-free rate of PCNL was significantly high than that of fURL (RR: 1.07; $95 \% \mathrm{Cl}: 1.03,1.12 ; P=0.0004$ ). The decline of hemoglobin in PCNL was significantly high than that of fURL (WMD: 1.07; 95\% Cl: $0.54,1.61 ; P<0.0001$ ). The number of blood transfusion was significantly greater in the PCNL compared to the fURL (RR: $5.04 ; 95 \%$ Cl: 1.78 , 14.24; $P=0.002$ ). The incidence of postoperative bleeding or hematuria showed greater significantly difference in the PCNL compared to the fURL (RR: $2.72 ; 95 \% \mathrm{Cl}: 1.55,4.75 ; P=0.0005$ ). Operation time, fever, infection, perforation, requiring drug analgesia was not significantly different between two surgical procedures.
\end{abstract}

Conclusions: In the treatment of upper urinary tract stones, the stones clearance rate of PCNL is higher than fURL, and the safety of fURL is higher than PCNL.

Keywords: Percutaneous nephrolithotomy, Ureteroscopic lithotripsy, Upper urinary tract stones, Efficacy, Safety

\footnotetext{
* Correspondence: gzgyzgh@vip.tom.com

${ }^{\dagger}$ Yeda Chen, Yaoan Wen and Qingfeng Yu contributed equally to this work. Department of Urology, Minimally Invasive Surgery Center, The First Affiliated Hospital of Guangzhou Medical University, Guangdong Key Laboratory of Urology, Kangda Road 1\#, Haizhu District, Guangzhou 510230, Guangdong, China
}

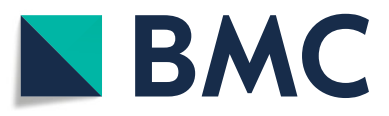

(c) The Author(s). 2020 Open Access This article is licensed under a Creative Commons Attribution 4.0 International License, which permits use, sharing, adaptation, distribution and reproduction in any medium or format, as long as you give appropriate credit to the original author(s) and the source, provide a link to the Creative Commons licence, and indicate if changes were made. The images or other third party material in this article are included in the article's Creative Commons licence, unless indicated otherwise in a credit line to the material. If material is not included in the article's Creative Commons licence and your intended use is not permitted by statutory regulation or exceeds the permitted use, you will need to obtain permission directly from the copyright holder. To view a copy of this licence, visit http://creativecommons.org/licenses/by/4.0/ The Creative Commons Public Domain Dedication waiver (http://creativecommons.org/publicdomain/zero/1.0/) applies to the data made available in this article, unless otherwise stated in a credit line to the data. 


\section{Background}

Upper urinary tract stones, including kidney stones and ureteral stones, are the most common diseases in urology clinical workers. For the treatment of upper urinary calculi, in the past, opening incision and stone removal were often used. The surgical injury was large, the complication rate was high, and the patient recovered for a long time. In recent years, with the development of medical equipment and medical technology, extracorporeal shock wave lithotripsy (ESWL), retrograde ureteroscopic lithotripsy (RIRS), percutaneous nephrolithotomy (PCNL) and other minimally invasive or non-invasive treatment methods appear successively $[1,2]$. Minimally invasive surgery is usually chosen after ESWL treatment is ineffective. PCNL, microchannel PCNL (mPCNL), ultra-fine passage percutaneous kidney mirror lithotripsy (UMP) and ultra-microchannel percutaneous nephrolithotomy (SMP) have become one of the preferred methods for clinical treatment of upper urinary calculi with its minimally invasive and highefficiency advantages. The appearance of ureteroscopy (fURL) had a huge impact on the treatment of upper urinary tract stones. Compared with ureteral hard and percutaneous nephrolithoscopy, it has a flexible lens body. Even if the stones are in the kidney, moving or descending into the ureter can also effectively crush the stone [3], thus having considerable advantages.

In the guidelines issued by the American Urological Association (AUA), fURL treatment is recommended for kidney stones $<2 \mathrm{~cm}$ in diameter, and PCNL is recommended for upper urinary calculi $>2 \mathrm{~cm}$ in diameter and more complicated stones. Jacquemet [4] et al. compared the calculus clearance rate and complication rate of 371 cases of renal calculi in different sites by fURL. It was found that there was no difference in the efficacy of fURL in the treatment of renal calculi and other renal stones. Professor Cheng [5] used fURL to treat staghorn calculi and achieved good results, and proposed that fURL can handle all the stones that PCNL can handle, and it is expected to replace high-risk surgery such as PCNL in the future. It has been reported in the literature that PCNL and fURL are both feasible and effective methods in the current comparative study of medium and large renal stone treatments [6].

Both procedures are the first-line method for the treatment of upper urinary calculi. Therefore, it is quite meaningful to compare the efficacy and safety of the two surgical procedures. At present, the clinical reports on the efficacy and safety of upper urinary calculi are mostly single-center, small-sample clinical controlled studies, and evidence-based medical evidence is lacking. We collect a clinical controlled study of these two surgical procedures for upper urinary calculi, using metaevidence medical analysis, comprehensive analysis and re-evaluation of published clinical controlled trials, in order to more scientifically evaluate their effectiveness and safety, providing a reference for clinical work.

\section{Methods}

A literature-search strategy, inclusion and exclusion criteria, outcome measurements, and methods of statistical analysis were prepared a priori according to the Preferred Reporting Items for Systematic Reviews and Meta-analysis (PRISMA) guidelines and the Meta-analysis of Observational Studies in Epidemiology Guidelines. Our study was based on data from previously published studies. Therefore, patients' consent or ethical approval were not necessary.

\section{Literature search}

A comprehensive literature retrieval was guided by independently by two investigators in Web of Science databases, PubMed, Embase and China National Knowledge Infrastructure databases (CNKI) with a cutoff date of Apr. 1, 2019. The following MeSH terms were used in search strategy: ("flexible ureteroscopic lithotripsy" OR "FURL" OR "RIRS" OR "percutaneous nephrolithotomy" OR "PCNL" OR "PNL") AND ("ureteral calculus" OR "Upper ureteralstones" OR "renal stones"). Besides, the references of other related articles were also handsearched for additional eligible studies.

\section{Inclusion and exclusion criteria}

Studies meeting the predetermined criteria were included: (1) patients with large $(>10 \mathrm{~mm})$ proximal ureteral stones and accompanied with secondary renal stones (<10 mm); (2) comparing PCNL(or mPCNL) and fURL; (3) both surgical techniques should be performed on adults; (4) the full text could be accessed online; (5) reporting at least one of clinical outcomes of interest (described in data extraction part). Exclusion criteria included: (1) only one procedure, no comparison study; (2) subjects < 18 years old; (3) repeated publications, select the latest published time; (4) a literature is less information so that data can not be obtained.

\section{Data extraction and quality assessment}

We screened the studies on the basis of inclusion and exclusion criteria. Two investigators independently extracted and reviewed the data from the eligible studies. Any disagreement was verified with a third investigator to resolve the dispute. Through a same standardized information collection table, the following data were extracted from all eligible studies: first author's name, publication year, country, primary site, study design, surgical technique, age, sex, stone burden, number of cases, stone free rate, operative time, decline of hemoglobin $(\mathrm{Hb})$, blood transfusion, bleeding/hematuria, fever/infection, perforation, requirements of drug analgesia for in the statistical analysis. 
The quality of eligible studies was performed by two investigators using the Newcastle-Ottawa Scale (NOS) [7] for cohort studies. This tool comprises three broad categories (selection of controls and cases, comparability and outcomes of study participants), and scores of 0-4, $0-2$, and $0-3$ are assigned for these three categories, respectively. Studies with final scores of $0-3,4-6$, and 7-9 were represented as low, moderate, and high quality, respectively. This quality score was used to measure the strength of each study's evidence. The Cochrane Collaboration's tool was used to assess the risk of bias of randomized controlled trials (RCTs).

\section{Data synthesis and statistical analysis}

All analyses were performed using RevMan 5.3 and Stata 12.0 software of the Cochrane Collaboration to compare the safety and efficacy of PCNL and fURL. Relative risk or odds ratio was used for dichotomous data, and weighted or standardized mean difference was used for the continuous data. All the outcomes were reported with 95\% confidence intervals (95\% CI). Cochran's test and $I^{2}$ statistic were used to assess the heterogeneity among studies [8]. When $I^{2}<50 \%$ or $P>0.05$ were considered as no heterogeneity and a fixed-effects model was performed. For significant heterogeneity among studies $\left(I^{2} \geq 50 \%\right.$ or $\left.p \leq 0.05\right)$, the random-effects model was applied. The funnel plot with Begg's correlation test and Egger's linear regression test were applied to assess the potential publication bias. The stability of the results was assessed with the sensitivity analysis.

\section{Results}

\section{Literature retrieval and analysis}

A flowchart of the literature search and study selection was shown in Fig. 1. A total of 8170 potential studies were found from the Embase, PubMed, Web of Science databases and CNKI. Based on the above-mentioned inclusion and exclusion criteria, a total of 19 studies were identified in the meta-analysis at last. A summary of the main characteristics of the included studies published from 2008 to 2017 was shown in Table 1, including 4 RCTs [8], 15 cohort studies [9-13, 15-17, 19-22, 24-26]. The 19 studies included 1822 individuals. Basic characteristics, such as age, sex ratio, stone burden and stone side, were described comparable between PCNL and fURL group in each study and the data was presented.

\section{Quality of the studies}

Figure 2 showed that all of the RCTs described suggested randomization. One study [9-13, 15-17, 19-22, 24-26] failed to collect complete outcome data. It was quite difficult to get a accurate result, so a high risk of bias was judged in this part for this

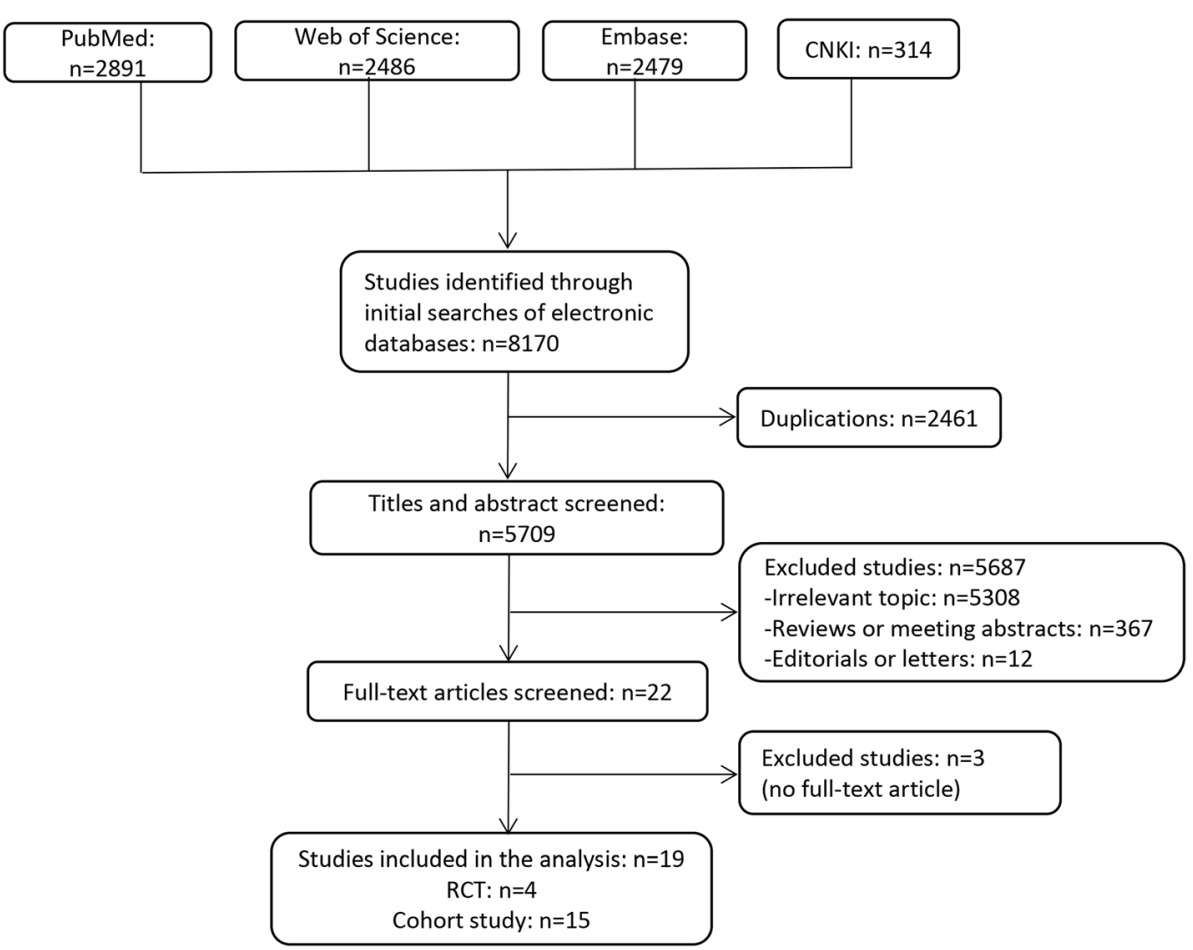

Fig. 1 Flow diagram of the literature search and selection 
Table 1 Main characteristic of the included studies

\begin{tabular}{|c|c|c|c|c|c|c|c|c|c|c|c|}
\hline \multirow[t]{2}{*}{ Reference, year } & \multirow[t]{2}{*}{ Nation } & \multirow{2}{*}{$\begin{array}{l}\text { primary } \\
\text { site }\end{array}$} & \multirow{2}{*}{$\begin{array}{l}\text { Study } \\
\text { design }\end{array}$} & \multirow{2}{*}{$\begin{array}{l}\text { Surgical } \\
\text { technique }\end{array}$} & \multirow{2}{*}{$\begin{array}{l}\text { Sample } \\
\text { size }\end{array}$} & \multicolumn{2}{|l|}{ Age (year) } & \multirow{2}{*}{$\begin{array}{l}\text { Sex } \\
(\mathrm{M} / \mathrm{F})\end{array}$} & \multicolumn{2}{|l|}{ Stone burden } & \multirow{2}{*}{$\begin{array}{l}\text { Stone } \\
\text { side } \\
\text { (left / right) }\end{array}$} \\
\hline & & & & & & $\overline{M e a n} \pm S D$ & $\overline{\text { Median } \pm \text { range }}$ & & $($ Mean \pm SD) & $\overline{\text { Median } \pm \text { range }}$ & \\
\hline \multirow[t]{2}{*}{ Aboutaleb, 2012 [9] } & \multirow[t]{2}{*}{ Kuwait } & \multirow{2}{*}{$\begin{array}{l}\text { Lower } \\
\text { calyx }\end{array}$} & \multirow[t]{2}{*}{ CS } & PCNL & 19 & $45.33 \pm 14.30$ & - & $14 / 5$ & $17.30 \pm 3.30$ & - & ND \\
\hline & & & & fURL & 13 & $47.20 \pm 15.20$ & - & $7 / 6$ & $14.50 \pm 3.20$ & - & ND \\
\hline \multirow[t]{2}{*}{ Armagan, 2015 [10] } & \multirow[t]{2}{*}{ Turkey } & \multirow[t]{2}{*}{ Kidney } & \multirow[t]{2}{*}{ CS } & $\mathrm{mPCNL}$ & 68 & $43.60 \pm 18.90$ & - & $35 / 33$ & $13.70 \pm 4.20$ & - & ND \\
\hline & & & & fURL & 59 & $49.30 \pm 15.30$ & - & $36 / 23$ & $14.40 \pm 3.10$ & - & ND \\
\hline \multirow[t]{2}{*}{ Bozkur, 2011 [11] } & \multirow[t]{2}{*}{ Turkey } & \multirow{2}{*}{$\begin{array}{l}\text { Lower } \\
\text { calyx }\end{array}$} & \multirow[t]{2}{*}{ CS } & PCNL & 42 & $47.40 \pm 15.50$ & - & $25 / 17$ & $1.70 \pm 0.12$ & - & $20 / 22$ \\
\hline & & & & fURL & 37 & $41.20 \pm 13.60$ & - & $21 / 16$ & $1.65 \pm 0.69$ & - & $19 / 18$ \\
\hline \multirow[t]{2}{*}{ Chung, 2008 [12] } & America & Kidney & CS & PCNL & 15 & - & $58.00^{\mathrm{a}}$ & $40 / 60$ & - & $1.80(1.0-2.0)$ & $60 / 40$ \\
\hline & & & & fURL & 12 & - & $58.50^{\mathrm{a}}$ & $58 / 42$ & - & $1.25(1.0-1.9)$ & $58 / 42$ \\
\hline Ferroud, 2011 [13] & French & Kidney & CS & $\mathrm{mPCNL}$ & 101 & $51.70 \pm 16.10$ & - & $80 / 21$ & $8.90 \pm 2.70$ & - & ND \\
\hline & & & & fURL & 43 & $49.20 \pm 14.80$ & - & $28 / 15$ & $8.50 \pm 3.20$ & - & ND \\
\hline Gu, 2013 [14] & China & Upper & $\mathrm{RCT}$ & $\mathrm{mPCNL}$ & 30 & $42.50 \pm 10.10$ & - & $17 / 13$ & $17.27^{\mathrm{a}}$ & - & $16 / 14$ \\
\hline & & ureter & & fURL & 29 & $44.22 \pm 13.00$ & - & $18 / 11$ & $16.23^{\mathrm{a}}$ & - & $12 / 17$ \\
\hline $\mathrm{Hu}, 2016$ [15] & China & ureter & CS & $\mathrm{mPCNL}$ & 104 & $65.50 \pm 4.90$ & - & $56 / 48$ & $15.80 \pm 3.40$ & - & $53 / 51$ \\
\hline & & & & fURL & 80 & $65.10 \pm 5.20$ & - & $45 / 35$ & $15.80 \pm 3.40$ & - & $47 / 33$ \\
\hline Kirac, 2013 [16] & Turkey & Lower & CS & $\mathrm{mPCNL}$ & 37 & $41.02 \pm 10.30$ & - & $25 / 12$ & $10.50 \pm 2.20$ & - & $16 / 22$ \\
\hline & & & & fURL & 36 & $37.80 \pm 8.70$ & - & $22 / 14$ & $10.20 \pm 2.90$ & - & $14 / 22$ \\
\hline Kruck, 2013 [17] & Germany & Kidney & CS & $\mathrm{mPCNL}$ & 172 & $53.30 \pm 14.80$ & - & $109 / 63$ & $12.60 \pm 9.50$ & - & ND \\
\hline & & & & fURL & 108 & $50.00 \pm 16.70$ & - & $69 / 39$ & $6.80 \pm 6.90$ & - & ND \\
\hline Kumar, 2015 [18] & India & Lower & $\mathrm{RCT}$ & $\mathrm{mPCNL}$ & 41 & $33.70 \pm 1.60$ & - & $20 / 21$ & $13.30^{\mathrm{a}}$ & - & $22 / 19$ \\
\hline & & & & fURL & 43 & $33.40 \pm 1.40$ & - & $20 / 23$ & $13.10^{\mathrm{a}}$ & - & $22 / 21$ \\
\hline Lee, 2015 [6] & Korea & Kidney & $\mathrm{RCT}$ & $\mathrm{mPCNL}$ & 35 & $59.30 \pm 13.30$ & - & $28 / 7$ & $39.10^{\mathrm{a}}$ & - & $21 / 14$ \\
\hline & & & & fURL & 33 & $55.80 \pm 11.20$ & - & $28 / 5$ & $28.90^{\mathrm{a}}$ & - & $23 / 10$ \\
\hline Ozgor, 2016 [19] & Turkey & Kidney & CS & $\mathrm{mPCNL}$ & 56 & $51.40 \pm 14.30$ & - & $25 / 31$ & $19.50 \pm 3.90$ & - & $25 / 31$ \\
\hline & & & & fURL & 56 & $54.20 \pm 10.60$ & - & $22 / 34$ & $18.30 \pm 3.20$ & - & $37 / 19$ \\
\hline Ozgor, 2018 [20] & Turkey & Kidney & CS & $\mathrm{mPCNL}$ & 58 & $66.90 \pm 5.90$ & - & $28 / 30$ & $20.30 \pm 5.60$ & - & ND \\
\hline & & & & fURL & 60 & $67.70 \pm 6.70$ & - & $33 / 27$ & $19.00 \pm 4.50$ & - & ND \\
\hline Pan, 2013 [21] & China & Kidney & CS & $\mathrm{mPCNL}$ & 59 & $49.37 \pm 14.20$ & - & $36 / 20$ & $22.37 \pm 2.70$ & - & $23 / 36$ \\
\hline & & & & fURL & 56 & $49.32 \pm 13.70$ & - & $37 / 22$ & $22.28 \pm 2.60$ & - & $30 / 26$ \\
\hline Sabnis, 2012 [22] & India & Kidney & CS & $\mathrm{mPCNL}$ & 32 & $44.48 \pm 12.36$ & - & $19 / 13$ & $1.52 \pm 0.33$ & - & $10 / 22$ \\
\hline & & & & fURL & 32 & $49.28 \pm 12.19$ & - & $25 / 7$ & $1.42 \pm 0.34$ & - & $16 / 16$ \\
\hline Sabnis, 2013 [23] & India & Kidney & $\mathrm{RCT}$ & $\mathrm{mPCNL}$ & 35 & $38.60 \pm 14.60$ & - & $22 / 13$ & $11.00^{\mathrm{a}}$ & - & 16/19 \\
\hline & & & & fURL & 35 & $43.70 \pm 12.10$ & - & $24 / 11$ & $10.40^{\mathrm{a}}$ & - & $18 / 17$ \\
\hline Schoenthaler, & Germany & Kidney & CS & UMP & 30 & - & $54.30(19-72)$ & $17 / 13$ & - & $15.10(10-20)$ & ND \\
\hline & & & & fURL & 30 & - & $56.30(18-76)$ & ND & - & $14.40(10-20)$ & ND \\
\hline Wilhelm, 2015 [25] & Germany & Kidney & CS & UMP & 25 & - & $51.56(15-75)$ & $15 / 10$ & - & $19.28(10-35)$ & ND \\
\hline & & & & fURL & 25 & - & $51.36(19-77)$ & $19 / 6$ & - & $19.20(10-35)$ & ND \\
\hline Zhang, 2014 [26] & China & Upper & CS & $\mathrm{mPCNL}$ & 32 & $42.70 \pm 13.60$ & - & $24 / 8$ & $15.60 \pm 2.50$ & - & ND \\
\hline & & & & fURL & 44 & $43.30 \pm 11.00$ & - & $29 / 15$ & $14.90 \pm 2.30$ & - & ND \\
\hline
\end{tabular}

$R C T$ randomized controlled trial, CS cohort study, PCNL percutaneous nephrolithotomy, mPCNL minipercutaneous nephrolithotomy, fURL flexible ureteroscopic lithotripsy, $N D$ not demonstrated

${ }^{a}$ No SD or range was demonstrated in primary studies

study. Other studies had low risk of selection bias, performance bias, detection bias, attrition bias, reporting bias and other bias. Therefore, three RCTs $[14,18,23]$ were judged to be of high quality. The quality of 15 cohort studies was assessed using the NOS. As shown in Table 2, the highest quality score was 9 and the lowest was 6 . The 


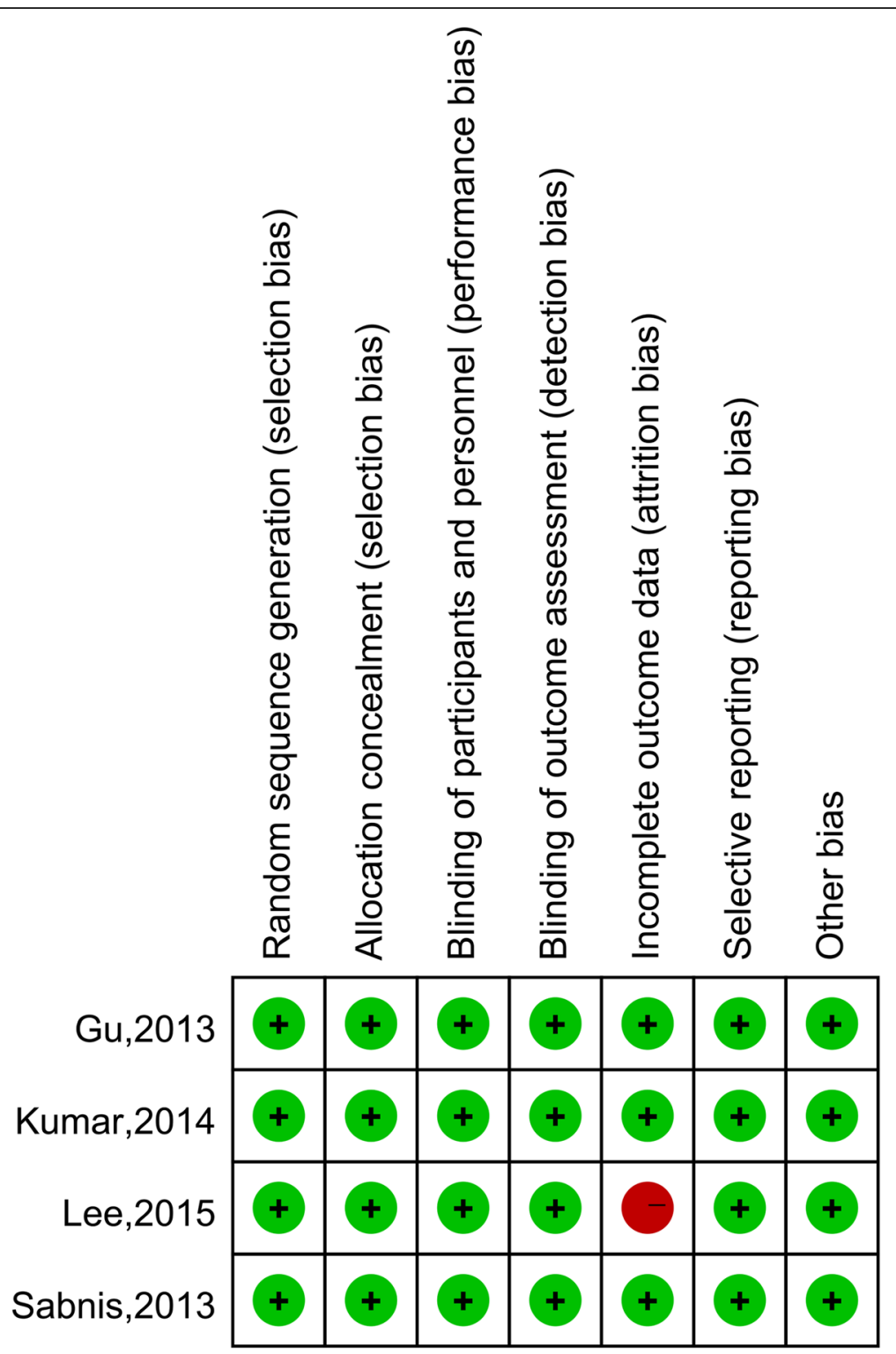

Fig. 2 Risk of bias for randomized controlled trials

average quality score for all cohort studies was 7.3. As a result, the cohort studies were considered high quality.

\section{Stone free rate}

Pooling the data from 19 studies [6, 9-26] demonstrated that the stone-free rate of PCNL group was significantly high than that of fURL group (RR: 1.07; 95\% CI: 1.03 , 1.12; $P=0.0004$; Fig. 3a).

\section{Operation time}

Pooling the data from 14 studies [6, 9-26] that assessed operation time showed no significant difference between PCNL group and fURL group (WMD: $-2.84 \mathrm{~min}$; 95\% CI: $-12.91,7.23$; $P=0.58$; Fig. $3 b$ ).

\section{Operative complications} Decline of $H B$

Meta-analysis of 7 studies $[6,10,15,16,21-23]$ by a random effects model showed that the decline in PCNL group was significantly high than that of fURL group (WMD: 1.07; 95\% CI: 0.54, 1.61; $P<0.0001$; Fig. 4a).

\section{Blood transfusion}

Meta-analysis of 6 studies $[6,10,15,16,21-23]$ by a fixed effects model showed that the number of blood transfusion was significantly greater in the PCNL group compared to the fURL group (RR: $5.04 ; 95 \% \mathrm{CI}: 1.78$, 14.24; $P=0.002$; Fig. 4b). 
Table 2 Quality assessment of included cohort studies

\begin{tabular}{|c|c|c|c|c|c|c|c|c|c|}
\hline \multirow{2}{*}{$\begin{array}{l}\text { Source } \\
\text { Author, year }\end{array}$} & \multicolumn{4}{|l|}{ Selection } & \multirow{2}{*}{$\begin{array}{l}\text { Comparability } \\
\text { select the most } \\
\text { important factor }\end{array}$} & \multicolumn{3}{|l|}{ Outcome } & \multirow[t]{2}{*}{ Scores } \\
\hline & $\begin{array}{l}\text { Representativeness } \\
\text { of the exposed } \\
\text { cohort }\end{array}$ & $\begin{array}{l}\text { Selection } \\
\text { of the non } \\
\text { exposed } \\
\text { cohort }\end{array}$ & $\begin{array}{l}\text { Ascertainment } \\
\text { of exposure }\end{array}$ & $\begin{array}{l}\text { Demonstration } \\
\text { that outcome } \\
\text { was not present } \\
\text { at start of study }\end{array}$ & & $\begin{array}{l}\text { Assessment } \\
\text { of outcome }\end{array}$ & $\begin{array}{l}\text { Follow-up long } \\
\text { enough }\end{array}$ & $\begin{array}{l}\text { Adequacy } \\
\text { of follow } \\
\text { up of } \\
\text { cohorts }\end{array}$ & \\
\hline $\begin{array}{l}\text { Aboutaleb, } \\
2012[9]\end{array}$ & - & - & $\star$ & $\star$ & $\star \star$ & $\star$ & $\star$ & $\star$ & 7 \\
\hline $\begin{array}{l}\text { Armagan, } \\
2015 \text { [10] }\end{array}$ & - & - & $\star$ & $\star$ & $\star \star$ & $\star$ & - & $\star$ & 6 \\
\hline $\begin{array}{l}\text { Bozkur, } \\
2011[11]\end{array}$ & $\star$ & $\star$ & $\star$ & $\star$ & $\star \star$ & $\star$ & $\star$ & $\star$ & 9 \\
\hline $\begin{array}{l}\text { Chung, } \\
2008 \text { [12] }\end{array}$ & - & - & $\star$ & $\star$ & $\star \star$ & $\star$ & $\star$ & $\star$ & 7 \\
\hline $\begin{array}{l}\text { Ferroud, } \\
2011 \text { [13] }\end{array}$ & - & - & $\star$ & $\star$ & $\star \star$ & $\star$ & $\star$ & $\star$ & 7 \\
\hline $\mathrm{Hu}, 2016$ [15] & $\star$ & $\star$ & $\star$ & $\star$ & $\star \star$ & $\star$ & $\star$ & $\star$ & 9 \\
\hline $\begin{array}{l}\text { Kirac, } \\
2013 \text { [16] }\end{array}$ & $\star$ & $\star$ & $\star$ & $\star$ & $\star \star$ & $\star$ & $\star$ & $\star$ & 9 \\
\hline $\begin{array}{l}\text { Kruck, } \\
2013[17]\end{array}$ & - & - & $\star$ & $\star$ & $\star \star$ & $\star$ & $\star$ & $\star$ & 7 \\
\hline $\begin{array}{l}\text { Ozgor, } \\
2016 \text { [19] }\end{array}$ & - & - & $\star$ & $\star$ & $\star \star$ & $\star$ & $\star$ & $\star$ & 7 \\
\hline $\begin{array}{l}\text { Ozgor, } 2018 \\
{[20]}\end{array}$ & - & - & $\star$ & $\star$ & $\star \star$ & $\star$ & $\star$ & $\star$ & 7 \\
\hline Pan, 2013 [21] & - & - & $\star$ & $\star$ & $\star \star$ & $\star$ & $\star$ & $\star$ & 7 \\
\hline $\begin{array}{l}\text { Sabnis, } \\
2012 \text { [22] }\end{array}$ & - & - & $\star$ & $\star$ & $\star \star$ & $\star$ & $\star$ & $\star$ & 7 \\
\hline $\begin{array}{l}\text { Schoenthaler, } \\
2015 \text { [24] }\end{array}$ & $\star$ & $\star$ & $\star$ & $\star$ & $\star \star$ & $\star$ & - & $\star$ & 8 \\
\hline $\begin{array}{l}\text { Wilhelm, } \\
2015 \text { [25] }\end{array}$ & - & - & $\star$ & $\star$ & $\star \star$ & $\star$ & - & $\star$ & 6 \\
\hline $\begin{array}{l}\text { Zhang, } \\
2014 \text { [26] }\end{array}$ & - & - & $\star$ & $\star$ & $\star \star$ & $\star$ & - & $\star$ & 6 \\
\hline
\end{tabular}

${ }^{\mathrm{a} A}$ maximum of two stars can be awarded for select the most important factor or additional factor

\section{Bleeding or hematuria}

Pooling the data from 9 studies $[9,14,16,18,20-23,26]$ that assessed the incidence of postoperative bleeding or hematuria showed significantly greater difference in the PCNL group compared to the fURL group (RR: 2.72; 95\% CI: 1.55, 4.75; $P=0.0005$; Fig. 4c).

\section{Fever or infection}

Meta-analysis of 11 studies [6, 11, 14-16, 18, 20-23, 26] by a fixed effects model showed the incidence of postoperative fever or infection was not signifcantly different in the PCNL group compared to the fURL group (RR: 1.26; 95\% CI: 0.82, 1.95; $P=0.29$; Fig. 5a).

\section{Perforation}

Meta-analysis of 6 studies [6,11,14,21-23] by a fixed effects model showed the occurrence rate of pelvis or ureter perforation was not significantly different in the PCNL group compared to the fURL group (RR: 1.11; 95\% CI: 0.38, 3.25; $P=0.84$; Fig. 5b).

\section{Requiring drug analgesia}

Meta-analysis of 5 studies $[6,9,14,15,18]$ by a random effects model showed the rate of requiring drug analgesia after surgery was not significantly different in the PCNL group compared to the fURL group (RR: 1.23; 95\% CI: 0.59, 2.55; $P=0.58$; Fig. 5c).

\section{Publication Bias}

Begg's test and Egger's test were used to assess the publication bias of those studies. Funnel plot showed that there were no significant publication bias observed among those studies. As showed in Table 3, all of Begg's $p$ value and Egger's $\mathrm{p}$ value were not significant.

\section{Sensitivity analysis}

Sensitivity analysis was conducted to determine the influence of each eligible study on the overall outcome and test the robustness of all results above. When any individual study was excluded, the pooled result was not significantly changed, showing the robustness of the results. 


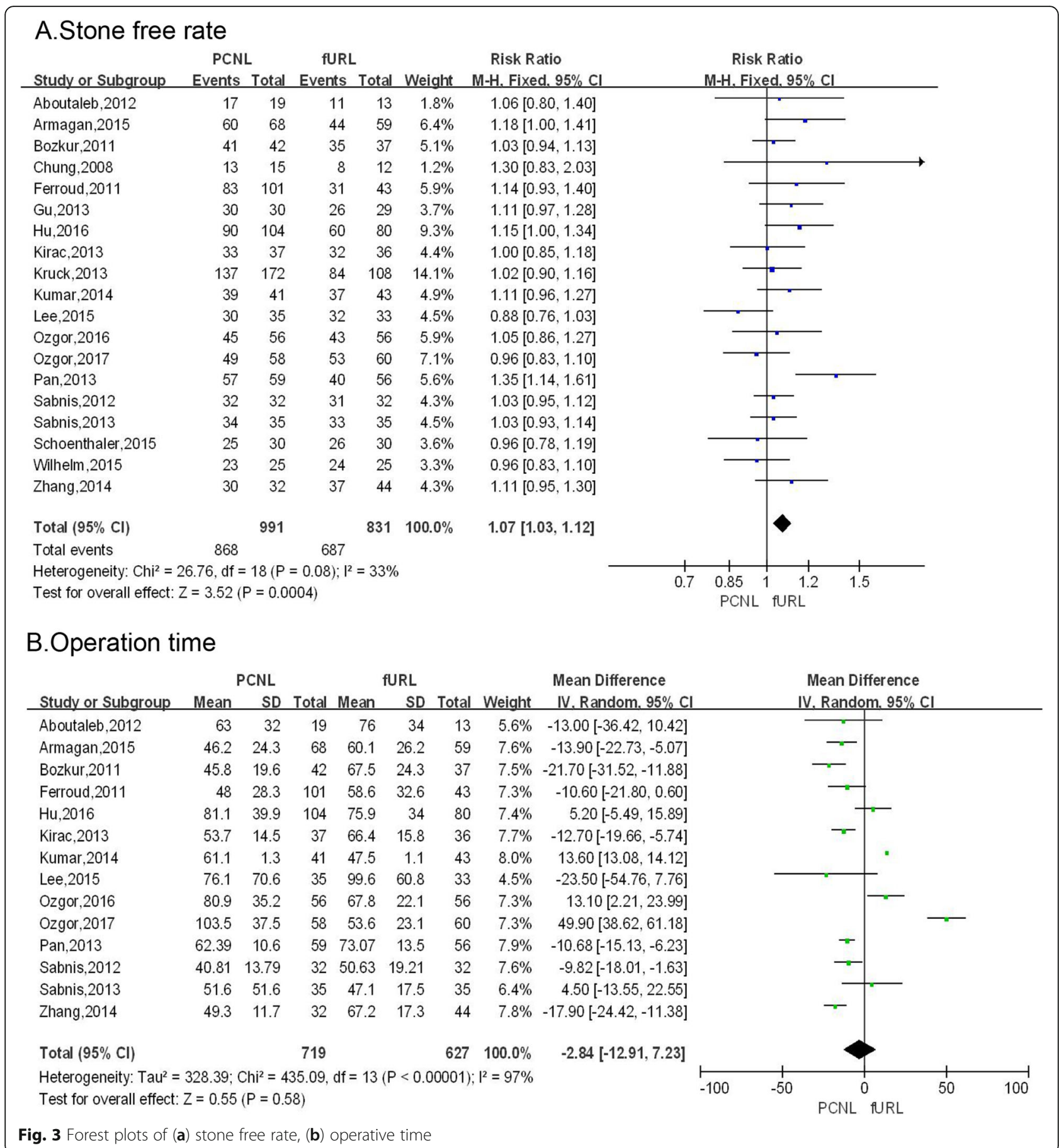

\section{Discussion}

Both PCNL and fURL are important methods for the treatment of upper urinary calculi. Our paper uses the meta-analysis method to comprehensively summarize the results of PCNL and fURL clinical studies to increase the sample size and improve the statistical power. According to the inclusion criteria and exclusion criteria, 19 studies were included, a total of 1822 cases of upper urinary calculi. In our paper, eight representative outcome indicators were selected to evaluate the efficacy and safety of the two surgical procedures.

Calculus clearance rate is the most important outcome measure for evaluating the effectiveness of PCNL and fURL in treating upper urinary calculi. Stone clearance is defined as follow-up $1 \sim 3$ months after the operation, the last imaging examination (X-ray, ultrasonography, or CT), no residual stone or residual stone less than $4 \mathrm{~mm}$ without clinical symptoms was successful. In our paper, 


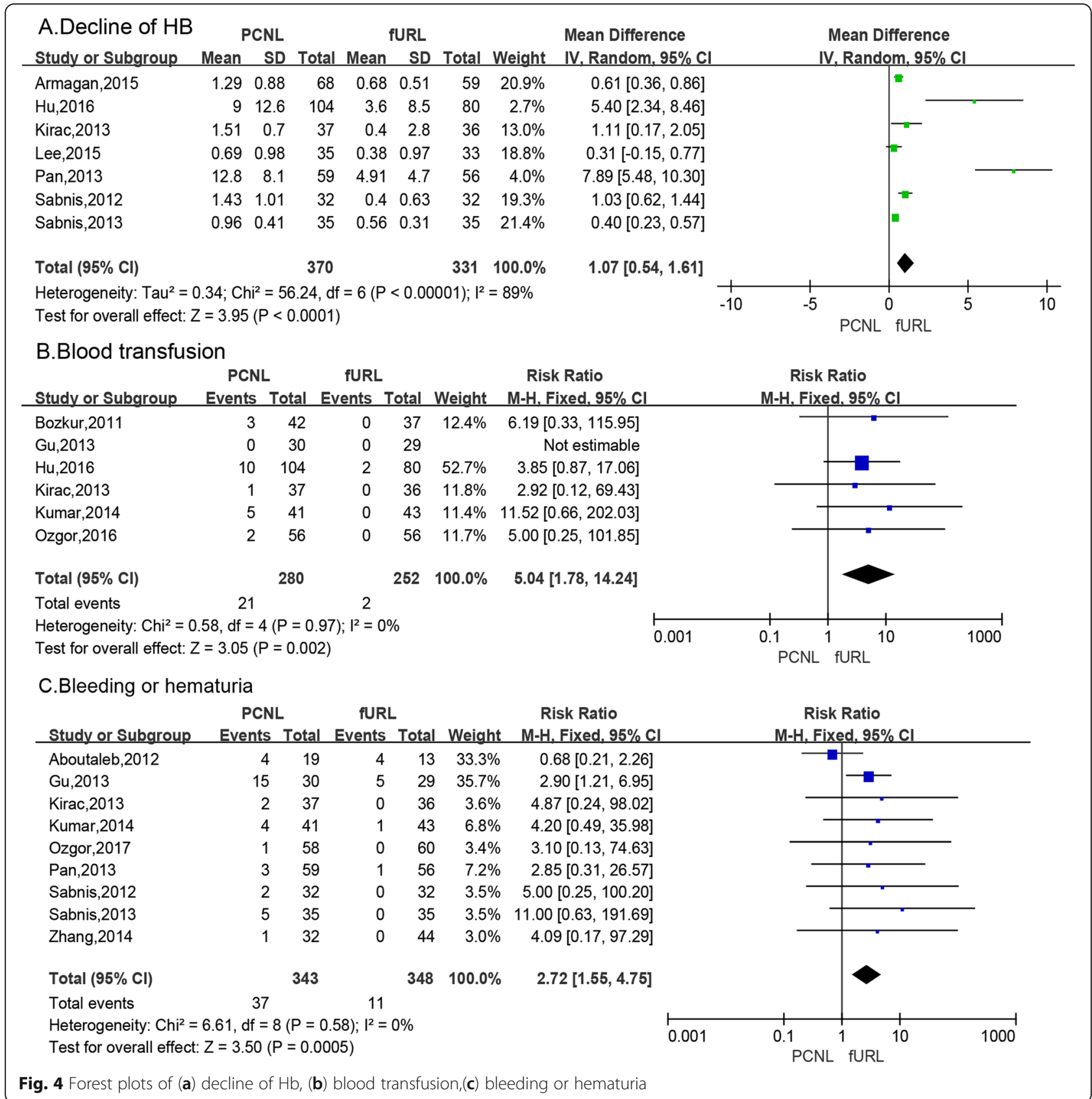

the combined analysis of the stone clearance rates of 19 studies showed that PCNL stone clearance rate is higher than fURL (RR:1.07, 95\% CI: 1.03, 1.12). Davis [27] et al. reported in their meta-analysis the stone clearance rate of $\mathrm{mPCNL}$ was higher than that of fURL, and the results were consistent with us. The efficacy of partial fURL in the treatment of large areas of kidney stones [28, 29] reported that stone size is the main parameter affecting the success rate of fURL. The success rate of fURL may be affected as the size of the stone changes. However, in the study by Davis [27] et al., the stone size was subgrouped separately, and the stone clearance rate of
mPCNL was higher in the kidney stone group $>2 \mathrm{~cm}$ or in the kidney stone group $<2 \mathrm{~cm}$ fURL, therefore, whether the two surgical stone removal rate is different due to the size of the stone is still controversial, we hope there is further evidence-based medical evidence.

The operation time is an indirect indicator of the patient undergoing surgery and anesthesia stress injury, and is related to the experience of surgeons and hospital equipment [15]. Some studies have reported that fURL surgery is longer than PCNL $[10,16,20,22,26]$, but in the comparison of the two surgical procedures, the time of PCNL operation was similar to fURL, and the 


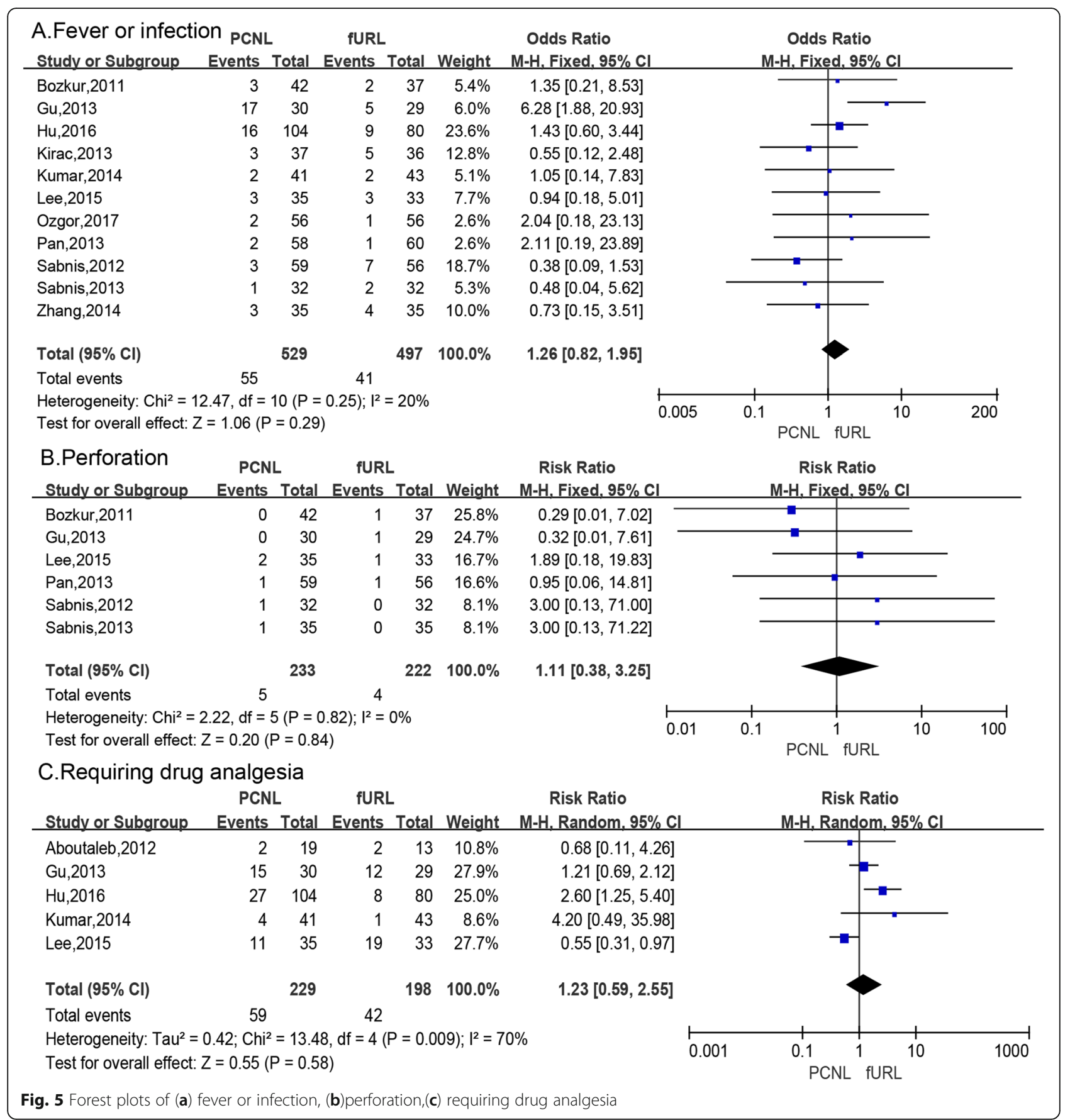

difference was not statistically significant (WMD: -2.84 min; 95\% CI: $-12.91,7.23 ; P=0.58)$.

Complications of upper urinary calculi surgery include renal collecting system or ureteral perforation and laceration, near organ injury, bacteremia, toxemia, infection, fever, intraoperative or postoperative bleeding, ureteral stricture, urine leaks, etc. The incidence of PCNL complications increases with the diameter of the working channel $[10,16,20,22,26,30]$. It has been reported that mPCNL (according to the working channel $\leq 20$ ) has a similar stone clearance rate and fewer complications than the standard channel PCNL (working channel = 30) [22, 31]. Based on the complication data provided by the 19 articles included in this article, the amount of $\mathrm{Hb}$ decreased before and after surgery, the proportion of patients requiring blood transfusion, postoperative hemorrhage or hematuria, infection or fever, postoperative analgesic drug use rate, treatment of upper urinary calculi complications of pelvic or ureteral 
Table 3 Results of publication bias testing

\begin{tabular}{|c|c|c|c|c|c|c|}
\hline \multirow[t]{2}{*}{ Study project } & \multirow{2}{*}{$\begin{array}{l}\text { Included } \\
\text { study }\end{array}$} & \multicolumn{2}{|c|}{ Begg testing } & \multicolumn{2}{|c|}{ Egger testing } & \multirow[t]{2}{*}{$95 \% \mathrm{Cl}$} \\
\hline & & $z$ & $P$ & $t$ & $P$ & \\
\hline Stone free rate & 19 & 1.19 & 0.234 & 1.21 & 0.244 & $-0.750,2.750$ \\
\hline Operative time & 14 & 0.11 & 0.913 & 1.51 & 0.156 & $-2.887,16.001$ \\
\hline Decline of $\mathrm{Hb}$ & 7 & 1.5 & 0.133 & -2.13 & 0.101 & $-5.691,0.756$ \\
\hline Blood transfusion & 6 & 0.24 & 0.806 & 0.84 & 0.463 & $-1.288,2.208$ \\
\hline Bleeding/hematuria & 9 & 0.73 & 0.466 & 1.36 & 0.216 & $-0.934,2.204$ \\
\hline Fever/infection & 12 & 0.89 & 0.373 & -1.22 & 0.251 & $-2.639,0.774$ \\
\hline Perforation & 6 & 0.38 & 0.707 & -0.6 & 0.578 & $-8.271,5.314$ \\
\hline Requiring drug analgesia & 5 & 0.24 & 0.806 & 0.56 & 0.615 & $-5.318,7.599$ \\
\hline
\end{tabular}

perforation were analyzed separately to understand the complications of PCNL and fURL in the treatment of upper urinary calculi.

The amount of $\mathrm{Hb}$ decreased, blood transfusion, bleeding or hematuria are important for evaluating the safety of surgery. In terms of the amount of $\mathrm{Hb}$ decreased before and after surgery, it can be seen that the amount of $\mathrm{Hb}$ decreased before and after PCNL surgery was more than fURL, suggesting that the amount of bleeding in PCNL was more (WMD: 1.07; 95\% CI: 0.54, 1.61; $P<0.0001)$. In terms of blood transfusion, it can be seen that PCNL requires more blood transfusion than fURL, suggesting that PCNL has more intraoperative and postoperative bleeding (RR: 5.04; 95\% CI: 1.78, 14.24; $P=0.002$ ). Postoperative bleeding or hematuria, suggesting that the incidence of postoperative bleeding after PCNL is higher than fURL (RR: 2.72; 95\% CI: 1.55 , 4.75; $P=0.0005)$. The decrease of $\mathrm{Hb}$ before and after surgery, the need for blood transfusion and postoperative hemorrhage or hematuria showed that PCNL had greater damage than fURL and more bleeding. The reason for the analysis may be that the kidney is rich in blood supply, and PCNL needs to puncture the kidney to establish a working channel. During the puncture and operation, it is easy to damage the interstitial blood vessels of the renal parenchyma, resulting in more intraoperative blood loss, and the injured renal blood vessels develop arteriovenous veins after operation. A arteriovenous fistula or pseudoaneurysm is a well known source of postoperative bleeding from PCNL [32]. After the operation, the renal fistula is retained, and the stimulation of the fistula can also cause renal vascular rupture. And fURL does not need to be established because it goes retrograde along the physiological channel into the lesion. As a channel, the damage to the body is small, the amount of bleeding is small, there is no need to place the fistula after operation, there is no continuous stimulation, and compared with PCNL, the complications of bleeding during fURL are strictly performed in the normalized operation, can be prevented [5].
Our performed a meta-analysis for the number of painful cases requiring painkillers after surgery, postoperative infection or fever, and the incidence of intraoperative pelvic or ureteral perforation. For the classification of pain, most studies used VAS visual scores [6, 22, 23], but this method is subjective. The use of analgesic drugs is associated with hospital policies, doctors' experience, patient's appeals, so there is heterogeneity. It can be seen that there is no statistical difference in the number of cases requiring painkillers and analgesia after PCNL and fURL (RR: 1.23 ; 95\% CI: 0.59, 2.55; $P=0.58$ ). There was no significant difference in the incidence of postoperative infection or fever between PCNL and fURL (RR: 1.26; 95\% CI: $0.82,1.95 ; P=0.29$ ). There was no significant difference in the incidence of pelvic or ureteral perforation between the two surgical procedures (RR: 1.11; 95\% CI: 0.38, 3.25; $P=0.84$ ).

In summary, PCNL and fURL have advantages and disadvantages in the treatment of upper urinary calculi. PCNL has higher stone clearance rate than fURL, and fURL has the advantage of less intraoperative/postoperative bleeding. Therefore, the appropriate surgical method should be selected according to the specific conditions of the patient, the experience of the doctor, and the conditions of the hospital.

\section{Conclusion}

In the treatment of upper urinary tract stones, the stones clearance rate of PCNL is higher than fURL. The Decline of $\mathrm{HB}$, the number of blood transfusion, the incidence of postoperative bleeding or hematuria in PCNL group was significantly high than that of fURL group, so the safety of fURL is higher than PCNL. Therefore, appropriate surgical methods should be selected according to different situations.

\section{Abbreviations}

ESWL: Extracorporeal shock wave lithotripsy; RIRS: Retrograde ureteroscopic lithotripsy; PCNL: Percutaneous nephrolithotomy; mPCNL: Microchannel PCNL; UMP: Ultra-fine passage percutaneous kidney mirror lithotripsy; SMP: Ultra-microchannel percutaneous nephrolithotomy; fURL: Ureteroscopy; 
AUA: The American Urological Association; PRISMA: The Preferred Reporting Items for Systematic Reviews and Meta-analysis; CNKI: China National Knowledge Infrastructure databases; Hb: hemoglobin; NOS: The NewcastleOttawa Scale; RCTs: Randomized controlled trials; 95\% Cl: 95\% confidence intervals

\section{Acknowledgements}

Not applicable.

\section{Authors' contributions}

YDC, YAW and QFY: Study conception and design, data collection and management; XLD and WQW: data collection and analysis, preparation of figures and tables; YDC, QFY and GHZ: Writing and revision of the manuscript. All authors read and approved the final manuscript.

\section{Funding}

This work was financed by grants from the National Natural Science Foundation of China (No. 81670643 and 81870483), the Collaborative Innovation Project of Guangzhou Education Bureau (No. 1201620011) the Guangzhou Science Technology and Innovation Commission (No. 201704020193), and the Science and Technology Planning Project of Guangdong Province (No. 2017B030314108)

No interferences occurred in carrying out the research project and in writing the manuscript that is the sole responsibility of the authors.

\section{Availability of data and materials}

The datasets used and/or analysed during the current study are available from the corresponding author on reasonable request.

\section{Ethics approval and consent to participate}

Not applicable.

\section{Consent for publication}

Not applicable.

\section{Competing interests}

The authors declare that they have no competing interests.

Received: 30 April 2019 Accepted: 13 July 2020

Published online: 25 July 2020

\section{References}

1. Wang Y, Hou J, Wen D, OuYang J, Meng J, Zhuang H. Comparative analysis of upper ureteral stones (>15 mm) treated with retroperitoneoscopic ureterolithotomy and ureteroscopic pneumatic lithotripsy. Int Urol Nephrol. 2010:42(4):897-901.

2. Zhu Z, Xi Q, Wang S, Liu J, Ye Z, Yu X, Bai J, Li C. Percutaneous Nephrolithotomy for proximal ureteral calculi with severe Hydronephrosis: assessment of different Lithotriptors. J Endourol. 2010;24(2):201-5.

3. Argyropoulos A, Tolley D. SWL is more cost-effective than Ureteroscopy and holmium:YAG laser lithotripsy for ureteric stones: a comparative analysis for a tertiary referral Centre. J Clin Urol. 2010;2:65-71.

4. Jacquemet B, Martin L, Pastori J, Bailly V, Guichard G, Bernardini S, Chabannes E, Bittard H, Kleinclauss F. Comparison of the efficacy and morbidity of flexible ureterorenoscopy for lower pole stones compared with other renal locations. J Endourol. 2014;28(10):1183-7.

5. Cheng Y, Liu G. Development and prospect of ureteroscopic lithotripsy for treatment of staghorn calculi. J Min Inv Urol. 2013;2:163-6.

6. Lee JW, Park J, Lee SB, Son H, Cho SY, Jeong H. Mini-percutaneous Nephrolithotomy vs retrograde Intrarenal surgery for renal stones larger than $10 \mathrm{~mm}$ : a prospective randomized controlled trial. Urology. 2015;86(5): 873-7.

7. Stang A. Critical evaluation of the Newcastle-Ottawa scale for the assessment of the quality of nonrandomized studies in meta-analyses. Eur J Epidemiol. 2010;25(9):603-5.

8. Higgins JP, Thompson SG. Quantifying heterogeneity in a meta-analysis. Stat Med. 2002;21(11):1539-58.

9. Aboutaleb H, El-Shazly M, Badr EM. Lower pole midsize $(1-2 \mathrm{~cm})$ calycea stones: outcome analysis of 56 cases. Urol Int. 2012;89(3):348-54.

10. Armagan A, Karatag T, Buldu I, Tosun M, Basibuyuk I, Istanbulluoglu MO, Tepeler A. Comparison of flexible ureterorenoscopy and micropercutaneous nephrolithotomy in the treatment for moderately size lower-pole stones. World J Urol. 2015:33(11):1827-31.

11. Bozkurt OF, Resorlu B, Yildiz Y, Can CE, Unsal A. Retrograde intrarenal surgery versus percutaneous nephrolithotomy in the management of lower-pole renal stones with a diameter of 15 to $20 \mathrm{~mm}$. J Endourol. 2011; 25(7):1131-5.

12. Chung Bl, Aron M, Hegarty NJ, Desai MM. Ureteroscopic versus percutaneous treatment for medium-size $(1-2-\mathrm{cm})$ renal calculi. J Endourol. 2008;22(2):343-6.

13. Ferroud V, Lapouge $O$, Dousseau A, Rakototiana A, Robert G, Ballanger P. Flexible ureteroscopy and mini percutaneous nephrolithotomy in the treatment of renal lithiasis less or equal to $2 \mathrm{~cm}$. Prog Urol. 2011;21(2): $79-84$

14. Gu XJ, Lu JL, Xu Y. Treatment of large impacted proximal ureteral stones: randomized comparison of minimally invasive percutaneous antegrade ureterolithotripsy versus retrograde ureterolithotripsy. World J Urol. 2013; 31(6):1605-10.

15. Hu H, Lu Y, He D, Cui L, Zhang J, Zhao Z, Qin B, Wang Y, Lin F, Wang S. Comparison of minimally invasive percutaneous nephrolithotomy and flexible ureteroscopy for the treatment of intermediate proximal ureteral and renal stones in the elderly. Urolithiasis. 2016:44(5):427-34.

16. Kirac M, Bozkurt OF, Tunc L, Guneri C, Unsal A, Biri H. Comparison of retrograde intrarenal surgery and mini-percutaneous nephrolithotomy in management of lower-pole renal stones with a diameter of smaller than 15 mm. Urolithiasis. 2013;41(3):241-6.

17. Kruck S, Anastasiadis AG, Herrmann TR, Walcher U, Abdelhafez MF, Nicklas AP, Holzle L, Schilling D, Bedke J, Stenzl A, et al. Minimally invasive percutaneous nephrolithotomy: an alternative to retrograde intrarenal surgery and shockwave lithotripsy. World J Urol. 2013;31(6):1555-61.

18. Kumar A, Kumar N, Vasudeva P, Kumar JS, Kumar R, Singh H. A prospective, randomized comparison of shock wave lithotripsy, retrograde intrarenal surgery and miniperc for treatment of 1 to $2 \mathrm{~cm}$ radiolucent lower calyceal renal calculi: a single center experience. J Urol. 2015;193(1):160-4.

19. Ozgor F, Tepeler A, Elbir F, Sarilar O, Gurbuz ZG, Armagan A, Binbay M, Tasci Al. Comparison of miniaturized percutaneous nephrolithotomy and flexible ureterorenoscopy for the management of $10-20 \mathrm{~mm}$ renal stones in obese patients. World J Urol. 2016;34(8):1169-73.

20. Ozgor F, Yanaral F, Savun M, Ozdemir H, Caglar U, Sarilar O. Comparison of miniaturized percutaneous nephrolithotomy and flexible ureterorenoscopy for moderate size renal stones in elderly patients. Kaohsiung J Med Sci. 2018;34(6):352-6.

21. Pan J, Chen $Q$, Xue W, Chen $Y$, Xia L, Chen H, Huang Y. RIRS versus $m P C N L$ for single renal stone of $2-3 \mathrm{~cm}$ : clinical outcome and cost-effective analysis in Chinese medical setting. Urolithiasis. 2013;41(1):73-8.

22. Sabnis RB, Jagtap J, Mishra S, Desai M. Treating renal calculi $1-2 \mathrm{~cm}$ in diameter with minipercutaneous or retrograde intrarenal surgery: a prospective comparative study. BJU Int. 2012:110(8 Pt B):E346-9.

23. Sabnis RB, Ganesamoni R, Doshi A, Ganpule AP, Jagtap J, Desai MR. Micropercutaneous nephrolithotomy (microperc) vs retrograde intrarenal surgery for the management of small renal calculi: a randomized controlled trial. BJU Int. 2013;112(3):355-61.

24. Schoenthaler M, Wilhelm K, Hein S, Adams F, Schlager D, Wetterauer U, Hawizy A, Bourdoumis A, Desai J, Miernik A. Ultra-mini PCNL versus flexible ureteroscopy: a matched analysis of treatment costs (endoscopes and disposables) in patients with renal stones $10-20 \mathrm{~mm}$. World J Urol. 2015; 33(10):1601-5.

25. Wilhelm K, Hein S, Adams F, Schlager D, Miernik A, Schoenthaler M. Ultramini PCNL versus flexible ureteroscopy: a matched analysis of analgesic consumption and treatment-related patient satisfaction in patients with renal stones 10-35 mm. World J Urol. 2015:33(12):2131-6.

26. Zhang $Y, Y u$ CF, Jin SH, Zhu H, Na YQ. A prospective comparative study between minimally invasive percutaneous nephrolithotomy in supine position and flexible ureteroscopy in the management of single large stone in the proximal ureter. Urology. 2014;83(5):999-1002.

27. Davis NF, Quinlan MR, Poyet C, Lawrentschuk N, Bolton DM, Webb D, Jack GS. Miniaturised percutaneous nephrolithotomy versus flexible ureteropyeloscopy: a systematic review and meta-analysis comparing clinical efficacy and safety profile. World J Urol. 2018:36(7):1127-38.

28. Breda A, Ogunyemi O, Leppert JT, Lam JS, Schulam PG. Flexible Ureteroscopy and laser lithotripsy for single Intrarenal stones $2 \mathrm{~cm}$ or greater-is this the new frontier? J Urol. 2008;179(3):981-4. 
29. Knoll T, Jessen JP, Honeck P, Wendt-Nordahl G. Flexible ureterorenoscopy versus miniaturized PNL for solitary renal calculi of $10-30 \mathrm{~mm}$ size. World Urol. 2011;29(6):755-9.

30. Yamaguchi A, Skolarikos A, Buchholz NP, Chomon GB, Grasso M, Saba P, Nakada S, de la Rosette J. Operating times and bleeding complications in percutaneous nephrolithotomy: a comparison of tract dilation methods in 5,537 patients in the clinical research Office of the Endourological Society Percutaneous Nephrolithotomy Global Study. J Endourol. 2011;25(6):933-9.

31. Resorlu B, Kara C, Unsal A. Prospective comparative study of Miniperc and standard PNL for treatment of 1 to $2 \mathrm{~cm}$ size renal stone. BJU Int. 2011; 108(7):E160 E160-E162.

32. Ganpule AP, Shah DH, Desai MR. Postpercutaneous nephrolithotomy bleeding: aetiology and management. Curr Opin Urol. 2014;24(2):189-94.

\section{Publisher's Note}

Springer Nature remains neutral with regard to jurisdictional claims in published maps and institutional affiliations.

Ready to submit your research? Choose BMC and benefit from:

- fast, convenient online submission

- thorough peer review by experienced researchers in your field

- rapid publication on acceptance

- support for research data, including large and complex data types

- gold Open Access which fosters wider collaboration and increased citations

- maximum visibility for your research: over $100 \mathrm{M}$ website views per year

At BMC, research is always in progress.

Learn more biomedcentral.com/submissions 